\title{
Brain Mechanisms of Extinction of the Classically Conditioned Eyeblink Response
}

\author{
Karla Robleto, ${ }^{1}$ Andrew M. Poulos, and Richard F. Thompson \\ University of Southern California, Neuroscience Program, Los Angeles, California, USA
}

\begin{abstract}
It is well established that the cerebellum and its associated circuitry are essential for classical conditioning of the eyeblink response and other discrete motor responses (e.g., limb flexion, head turn, etc.) learned with an aversive unconditioned stimulus (US). However, brain mechanisms underlying extinction of these responses are still relatively unclear. Behavioral studies have demonstrated extinction as an active learning process distinct from acquisition. Experimental data in eyeblink conditioning suggest that plastic changes specific to extinction may play an important role in this process. Both cerebellar and hippocampal systems may be involved in extinction of these memories. The nature of this phenomenon and identification of the neural substrates necessary for extinction of originally learned responses is the topic of this review.
\end{abstract}

Since Pavlov first described the phenomenon, classical conditioning has proven to be an extremely useful model in the study of learning and memory. Behaviorally, extinction is evidenced by a decrease in the frequency of the conditioned response (CR) due to the repeated presentation of the conditioned stimulus (CS) in the absence of the unconditioned stimulus (US). It has seemed clear that since Pavlov's (1927) original observations, extinction is not merely the fading away of a memory. The classical phenomena of spontaneous recovery and disinhibition, as well as re-exposure to the reinforcer (Rescorla and Heth 1975; Bouton 1984), change in context (Bouton and Swartzentruber 1991), sensitivity to changes in reinforcer value (Rescorla 1995), and marked savings in reacquisition (Scavio and Thompson 1979; Napier et al. 1992; Macrae and Kehoe 1999) all argue that the originally learned associations are in some manner preserved during extinction training (see also Falls 1998). The common explanation for these phenomena is that extinction induces new learning that somehow interferes with performance.

This current understanding of extinction has guided neural studies, which have tried to identify possible brain structures that could support this new learning. Likewise, as a form of learning, additional plastic changes, different from those involved in acquisition, may occur in extinction. Whether extinction engages the same brain sites necessary for acquisition is not yet clear.

Classical conditioning of the eyeblink regions in mammals has proven to be a most useful system for analysis of both behavioral and neural aspects of acquisition and retention of learned responses. This review will focus on extinction of basic associative learning using classical conditioning of discrete motor responses as the model. Extinction of other forms of classical conditioning and its neural basis (e.g., fear conditioning) are reviewed elsewhere (see Myers and Davis 2002) and are only mentioned briefly here.

Contemporary theories conceptualize extinction as a form of new learning that results in the inhibition of the original conditioned response. Spontaneous recovery has been consistently observed in a variety of conditioning protocols (see above) (Napier et al. 1992; Bouton 1993; Schreurs 1993). Bouton (2002) explained this recovery as the effects of ambiguity caused by memory of the excitatory and inhibitory association. Many stud-

\footnotetext{
'Corresponding author.
}

E-MAIL krobleto@usc.edu; FAX (213) 740-5687.

Article and publication are at http://www.learnmem.org/cgi/doi/10.1101/ Im.80004. ies have shown the importance of context specificity in extinction. Likewise, time could provide a form of temporal context to which extinction is highly sensitive. Thus, spontaneous recovery is seen when the CS is tested in a different temporal context and the subject cannot retrieve the memory of extinction. In a series of experiments using appetitive conditioning, Brooks and colleagues (Brooks et al. 1999; Brooks 2000; Brooks and Bowker 2001) confirmed this hypothesis by observing that cues presented during extinction training attenuate spontaneous recovery if presented during the recovery test. This would indicate a failure of retrieval of the inhibitory memory outside of the extinction context, given that delay would result in a new temporal context. In what is referred to as the "renewal effect", the capacity of the CS to evoke responses is renewed after extinction if the context is changed during CS testing, supporting Bouton's hypothesis.

Rapid reacquisition following extinction, noted above, provides strong support for preservation of the original responses. Recent studies on long-term memory of conditioned responses have further shown that reacquisition after long extinction testing intervals (i.e., 1, 2, 3, and $6 \mathrm{mo}$ ), is still very rapid, also suggesting that the original memory does not fade away, and is instead, to a great degree, retained (Schreurs 1993, 1998). Further proof can be seen in experiments that show a high degree of transfer to a novel CS even after conditioned responses to the original CS have been extinguished (Kehoe et al. 1984). In other words, acquisition is faster to a novel CS in subjects that have acquired an original CS-US association, an effect that can even be seen after extinction training of the original CS.

Experimental evidence has shown that a CS can enter concurrently into an inhibitory and excitatory association with the same US (Smith and Gormezano 1965; Tait and Saladin 1986; Barnet and Miller 1996; Delamater 1996). Strong evidence comes from an early experiment by Smith and Gormezano (1965) demonstrating that a single CS can simultaneously support robust conditioning and extinction. In this experiment, rabbits were trained to delay eyeblink conditioning using a tone CS. Following robust acquisition, rabbits received 11 alternating sessions of conditioning and extinction. Although CR expression during conditioning sessions remained robust, responding during CS alone sessions yielded a within-session extinction function that continued to decline across sessions. Also, in an elegant experiment, Tait and Saladin (1986) trained rabbits to a tone CS and a periorbital shock US. They subsequently trained them for lick 
suppression conditioned responses in a backward-conditioning protocol, in which the US preceded the CS. Backward conditioning is considered a form of inhibitory learning, as it retards acquisition when the pairings are subsequently done in a forward manner (CS-US). They observed that rabbits showed more lick suppression to the tone than control animals, indicating that the CS acted as an excitor. Training was subsequently resumed by switching to a forward-conditioning protocol (CS-US) presenting the same stimuli, but now training for eyeblink-conditioned responses. The animals were found to be retarded in their acquisition of the conditioned response compared with control animals that had not been exposed to backward training, indicating that the CS acted as an inhibitor. These results are important because they suggest that a single CS can simultaneously have inhibitory and excitatory associations with a US.

At a behavioral level, there is thus considerable evidence that extinction training somehow results in inhibition of at least expression of the original learned response. But the term "inhibition" used in this context does not necessarily imply neuronalsynaptic processes of inhibition. It is a behavioral descriptor.

\section{Neuronal Substrates of Extinction}

There are at least two key issues in terms of understanding the neuronal bases of extinction of learned responses, for example, (1) identification of the neuronal circuits and mechanisms that result in the new learning in extinction and inhibition of the original learned response, and (2) the loci in the brain where the original associations are still to some significant degree preserved.

The neuronal circuitry essential for classical conditioning of the eyeblink and other discrete responses learned with an aversive unconditioned stimulus has been largely identified, at least for acquisition and retention, and the most likely sites of neuronal plasticity (memory traces) have been, to a degree, localized (Thompson and Krupa 1994; Thompson et al. 1997; Yeo and Hesslow 1998; Nores et al. 2000; Steinmetz 2000; Woodruff-Pak and Steinmetz 2000; Christian and Thompson 2003). Consequently, it would seem an ideal system in which to analyze neuronal processes of extinction.

Briefly, in so far as acquisition is concerned, CR pathway exits from the interpositus nucleus ipsilateral to the trained eye via the superior cerebellar peduncle (scp) to the red nucleus, and subsequently, via descending rubral pathways, to the premotor and motor nuclei generating the CR. The CS pathway includes sensory relay nuclei and their projections via the pontine nuclei and other sources as mossy fibers to the cerebellum. The US pathway includes sensory (trigeminal) relays to the inferior olive and from there via climbing fibers to the cerebellum. The unconditioned response (UR) pathway includes both direct and indirect projections from the trigeminal nucleus to the motor nuclei generating the behavioral response, and need not involve the cerebellum.

The strongest evidence for localization of the putative sites of memory storage within this circuit has come from studies using methods of reversible inactivation. A very oversimplified schematic of the circuitry is shown in Figure 1 to illustrate loci that have been reversibly inactivated during acquisition training of the eyeblink response. In brief, reversible inactivation localized to the interpositus nucleus completely prevented acquisition (Krupa and Thompson 1997), but inactivation of the output from the interpositus nucleus, the superior peduncle, the red nucleus, and the motor nuclei did not prevent acquisition at all, even though such inactivations completely prevented expression of the CR (see Clark et al. 1992; Krupa et al. 1993, 1996; Nordholm et al. 1993; Hardiman et al. 1996). Collectively, these data clearly

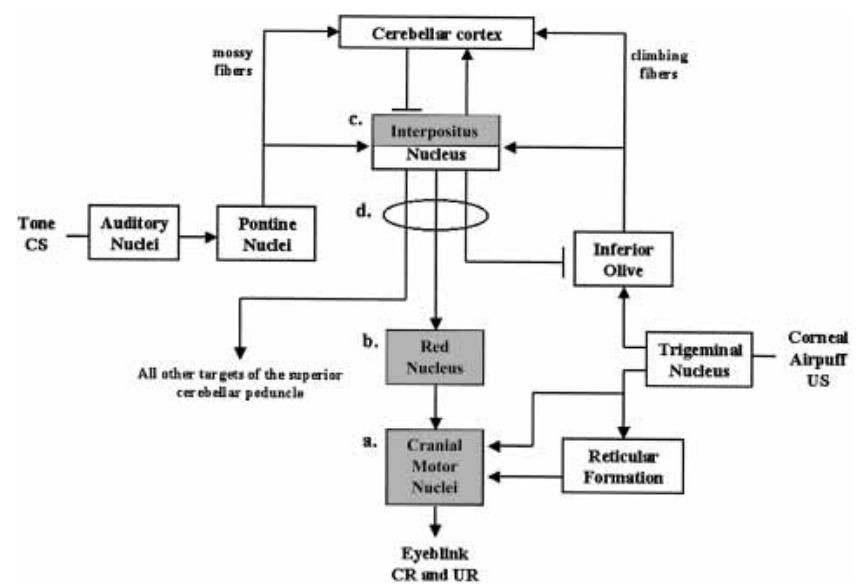

Figure 1 Highly simplified schematic of the cerebellum and associated brain circuitry essential for eyeblink conditioning. Shadowed boxes illustrate loci that have been previously inactivated during acquisition training. (a) Motor nuclei including facial (seventh), accessory (sixth), and adjacent reticular regions; (b) magnocellular red nucleus; (c) dorsal anterior interpositus; (d) superior cerebellar peduncle. (Modified with permission from the Annual Review of Neuroscience, Volume 17 (c) 1994 by Annual Reviews, www.annualreviews.org, Thompson and Krupa 1994).

show the essential plasticity for eyeblink conditioning to be localized to the cerebellum (for a detailed review, see Christian and Thompson 2003).

The role of the cerebellar cortex in acquisition is not yet clear. All workers agree that it is extremely important, indeed critical for normal learning, but whether or not it is essential remains controversial (see detailed discussion by Christian and Thompson 2003; see also Yeo 2004). In brief, two cortical regions have been implicated to play important roles in eyeblink conditioning, Larsell's hemispheric lobule VI (HVI) and the anterior lobe. HVI, the area of the cortex immediately dorsal to the interpositus, has been found to be involved in rate of eyeblink conditioning (Logan 1991) and possibly in maintaining the frequency of CR expression in well-trained animals (Yeo et al. 1984; Hardiman et al. 1988; but, see Woodruff-Pak et al. 1985; Lavond et al. 1987). Conversely, lesions of the anterior lobe have been found to affect timing and amplitude of the CR (Perret and Mauk 1995; K.S. Garcia et al. 1999; but, see McCormick and Thompson 1984).

Several lines of evidence argue strongly for learning-induced processes that develop in the interpositus, as opposed to developing elsewhere and being relayed to the interpositus. Infusion of muscimol localized entirely to the interpositus nucleus completely prevents learning and expression of the CR (Krupa and Thompson 1997). Although it is true that this treatment will block Purkinje GABAergic action on nuclear cells, the fact that animals show no savings at all after the inactivation has been removed demonstrates that no part of the memory trace has been formed in cerebellar cortex independent of the interpositus; otherwise, there would be savings. Other than the direct projections from the interpositus to the cerebellar cortex, all normal mossy and climbing fiber projections to the cortex are intact and functional (muscimol does not inactivate fibers). Projections from the interpositus to the cortex, either direct or indirect, would seem to play a key role in establishing plasticity in cortex.

In a recent study, we inactivated the relevant motor nuclei during CS alone extinction training of the conditioned eyeblink response in rabbits (Krupa and Thompson 2003). Results were very clear. Complete inactivation of the motor nuclei that generate the eyeblink CR and UR during CS alone extinction train-

\section{Learning \& Memory}

www.learnmem.org 
ing, given over 3 or $6 \mathrm{~d}$, completely prevented extinction, measured either by percent CR or CR amplitude. In postinactivation extinction training, extinction performance of the inactivation groups was identical to the initial extinction performance of the saline control groups; there is no savings in extinction (see Fig. 2). Consequently, inactivation of the motor nuclei during extinction training completely prevents the occurrence of extinction. Because complete inactivation of these same motor nuclei during acquisition training has no deleterious effect at all on learning of the CR, (Krupa et al. 1996), these results provide powerful additional evidence that acquisition and extinction processes differ, not only in behavioral properties, but also in neuronal substrates in eyeblink conditioning.

Pavlov (1927), Rescorla (1997), and others have emphasized the possibility that extinction results in an inhibitory association between a stimulus and a particular response, which would disrupt performance despite the continued presence of the original associations (see, e.g., Rescorla and Wagner 1972). As Rescorla (1997) notes, one line of evidence favoring this view comes from the correlation between the amount of responding that occurs in extinction and the amount of deterioration that the extinction experience produces. Procedures that reduce responding during extinction reduce performance loss (Holland and Rescorla 1975), and procedures that augment responding during extinction amplify the loss resulting from nonreinforcement (Rescorla and Skucy 1969; Wagner 1971). Our finding that inactivation of the motor nuclei prevents extinction would seem to be supportive of this response-extinction hypothesis.

Yeo and associates (Hardiman et al. 1996; Ramnani and Yeo 1996) reported that reversible inactivation of the interpositus nuclear region with muscimol during CS alone extinction training completely prevented extinction (and completely prevented expression of the $\mathrm{CR}$ ). We have replicated this result using very low doses of muscimol $(1 \mu \mathrm{g}$ in $0.1 \mu \mathrm{L})$ infused in the interpositus (Robleto and Thompson 2003). On the basis of earlier studies (Krupa et al. 1993) actions of these very doses do not appear to spread beyond the interpositus. These results would seem to implicate the interpositus in extinction.

The fact that inactivation of the motor nuclei prevented extinction of the CR suggested an alternative interpretation,
A

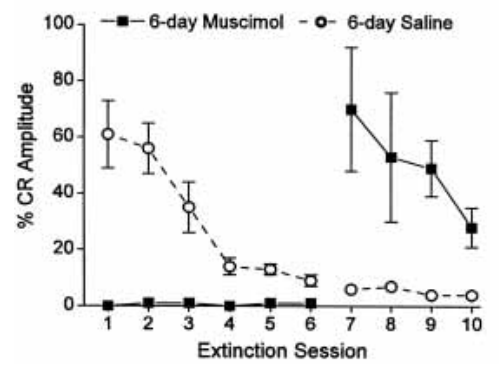

B

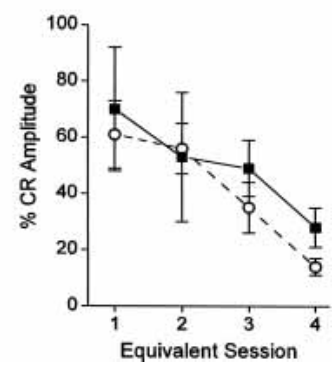

Figure 2 (A) Mean percentage CR amplitude for saline and experimental groups over the course of extinction training. Animals were infused over $6 \mathrm{~d}$ with either saline or the GABA-A agonist muscimol. As evidenced by $\mathrm{CR}$ performance during postinfusion extinction training, inactivation of the motor nuclei with muscimol completely prevented decrement in CR amplitudes. In contrast, saline control animals showed gradual decreases in CR amplitude that were significantly smaller than those of the muscimol group. (B) Mean percentage of CRs for the first four sessions of the saline control group and the last four sessions (no infusion) of the muscimol group. Results show that there is no difference between groups, demonstrating that muscimol inactivation prevented extinctionrelated reductions with no effects on subsequent extinction without mus cimol (Copyright 2003 by the Society for Neuroscience, Krupa and Thompson 2003). namely, that inactivation of the interpositus prevents extinction simply because it prevents performance of the CR, consistent with the response-extinction hypothesis.

To further test this hypothesis, we have inactivated with muscimol the region of the red nucleus critical for expression of the CR (K. Robleto and R.F. Thompson, unpubl.). After having been conditioned to asymptotic levels, animals were presented with seven daily sessions of tone alone presentation. Infusions of muscimol or saline were administered $1 \mathrm{~h}$ prior to extinction training and were discontinued after day 4 of training. Using the same low dose of muscimol that we used for interpositus inactivation during CS alone extinction training, these infusions completely prevented performance of the CR. Yet, extinction occurred during red nucleus inactivation! This result is consistent with the fact that red nucleus inactivation does not prevent learning of the CR, but would seem not to support the responseextinction hypothesis. Actually, the red nucleus infusions elicited small, tonic alterations in behavior, such as tilting of the head in a direction contralateral to the infusion site. The presence of these drug-induced behavioral responses could have concurrently activated brain pathways associated with the eyeblink response, resulting in an amount of responding sufficient to produce extinction, as studies on response inhibition have shown (i.e., Rescorla 1997).

Another possible explanation concerns context. Muscimol inactivation of the relevant motor nuclei on one side results in complete paralysis of the ipsilateral face and head musculature, which could provide a very different context for the animal. In marked contrast, inactivation of the relevant region of the red nucleus simply prevents performance of the eyeblink CR and little else, other than a slight turning of the head; in short, a much less-pronounced change in context. If so, the hippocampus may be involved in the motor nuclei inactivation effect on extinction (see Hippocampus section below).

In sum, these results demonstrate clearly that the neuronal bases of acquisition and extinction differ. Consistent with this view, there is considerable evidence using the conditioned fear paradigm that the neuronal substrates of acquisition and extinction may differ at both systems and molecular levels. In particular, the medial prefrontal cortex (rat) seems to play a more important role in extinction than in acquisition (Morgan et al. 1993; Quirk et al. 2000; Herry and Garcia 2002; Milad and Quirk 2002; but, see Gewirtz et al. 1997; R. Garcia et al. 1999). It appears that L-type voltage-gated calcium channels are required for extinction but not for acquisition or expression of conditioned fear to context of cue (Cain et al. 2002). It also appears that although NMDA receptors in the amygdala may be necessary for acquisition and long-term extinction (Falls et al. 1992; Lee and Kim 1998), they may not be necessary for short-term extinction (systemic administration; Santini et al. 2001). Finally, although protein synthesis in the amygdala is necessary for acquisition of conditioned fear to both context and cue stimuli (Bailey et al. 1999), it does not appear necessary for extinction of fear to context, at least with systemic injections of an inhibitor (Lattal and Abel 2001).

\section{The Inferior Olive-Climbing Fiber Reinforcement System}

Several lines of evidence support the view that the inferior olive (IO), and its climbing fiber projections to the cerebellum, serve as the essential reinforcement system for motor learning (Albus 1971; Eccles 1977; Ito 1982; Thompson 1989) region (Thompson et al. 1998). The critical region of the IO for eyeblink conditioning is the dorsal accessory olive (DAO), which receives predominately somatosensory input relayed from the spinal cord and appropriate cranial nuclei, including noceptive input (Brodal and Brodal 1981). 
At the beginning of training, the onset of the US evokes short latency unit responses by neurons in the face region of the DAO. Over the course of training, this evoked unit response gradually disappears in inverse correlation with the development of behavioral CRs (Sears and Steinmetz 1991). Lesions of the critical region of the inferior olive, the face representation in the $\mathrm{DAO}$, completely prevent learning if made before training, and result in extinction of the $\mathrm{CR}$ with continued paired training made after training (McCormick et al. 1985; Voneida et al. 1990, limb flexion in cat; Mintz et al. 1994). Neurons in this critical DAO region do not respond to auditory stimuli (CS), respond only to US onset, and show no learning-related activity. Electrical microstimulation of this region serves as a very effective US (Mauk et al. 1986; Steinmetz et al. 1989). Whatever response is elicited by stimulation of the IO-climbing fibers is easily learned to any neutral stimulus.

Immediate abolition of the CR has been observed in large IO lesion and inactivation studies (Yeo et al. 1986; Welsh and Harvey 1998), perhaps partially due to significant increases in Purkinje cell simple spike activity (Montarolo et al. 1982; Savio and Tempia 1985). Increased inhibition of Purkinje cells to the IP would prevent CR expression, which depends on sufficiently high-activity levels in the nuclei in order to occur.

The interpositus nucleus sends direct GABAergic projections to the DAO (Nelson et al. 1989). Hence, as learning-induced increases in interpositus neuron activity develop, inhibition of the DAO neurons will increase (Hesslow and Ivarsson 1996). This accounts for the fact that US-evoked activity in the DAO decreases as learning develops, consistent with the Rescorla and Wagner (1972) formulation. This also appears to serve as a part of the neural circuit essential for the behavioral learning phenomenon of blocking, where prior training to one CS, for example, tone, prevents subsequent learning to a light CS when it is then presented together with the tone in paired compound stimulus training (Kamin 1969). Infusion of picrotoxin in the DAO to block the GABA inhibition from the interpositus during compound stimulus training completely blocks the development of behavioral blocking (Kim et al. 1998). In other words, blocking interpositus inhibition of the IO greatly facilitates new learning.

In the context of extinction, preventing US activation of the IO-climbing fiber system by IO lesions results in extinction, even in the presence of continued CS-US paired training, whereas blocking inhibition of the IO greatly facilitates learning and would be expected to counteract normal CS alone extinction training. Both of these effects have been replicated and extended in important studies by Mauk and associates. Medina et al. (2002) examined the role of inhibitory and excitatory inputs to the climbing fibers in extinction by administering infusions of picrotoxin, a GABA A antagonist, and the AMPA receptor antagonist NBQX. It was found that infusions of picrotoxin to block inhibitory transmission from the interpositus to the IO prevented the extinction of CR's. Conversely, infusions of NBQX (which block excitatory input to climbing fibers) during paired CS-US presentation resulted in a gradual disappearance of CR's that was not different from extinction behavior observed during tone-alone presentations under normal conditions or with paired training following lesions of the DAO.

These studies indicate that changes in activity of the IO greatly contribute to the acquisition and extinction of the conditioned response. In extinction, IP inhibition would promote IO activity decreases below baseline levels, considering that the omission of the US would cease to excite climbing fibers. The strong IP inhibitory output that results during performance of the conditioned response without a US would then cause IO activity to decrease signaling changes that would ultimately allow extinction to occur. All of these results argue that the IO- climbing fiber system is the critical reinforcing or teaching system for motor learning, and that it plays a key role in extinction.

\section{The Locus of Preserved Memories}

A fundamental question concerning brain substrates of extinction is the locus or loci of the preserved memory. Current evidence would seem to suggest either the cerebellar cortex, the interpositus nucleus, or both as candidates. Gould and Steinmetz (1996) reported that multiunit activity in the interpositus correlated closely with the behavioral CR over both acquisition and extinction, showing complete absence of increased activity when the CR was fully extinguished. In contrast, multiunit activity in cerebellar cortex increased over acquisition, but did not decrease much during extinction of the CR. Although several different patterns of responses were seen for identified single Purkinje neurons, some 13 Purkinje cells showed increased responses over training and did not decrease over extinction. Such increased Purkinje neuron activity could promote inhibition of interpositus activity in extinction.

Perrett and Mauk (1995) reported that lesions of the anterior lobe of cerebellar cortex in well-trained animals prevented extinction of the behavioral CR. They separated two groups of such lesioned animals on the basis of response timing. Short latency CR animals did not show extinction, but normal latency CR animals did. More recently, K.S. Garcia et al. (1999) reported that anterior lobe-lesioned animals that displayed short-latency CRs showed no evidence at all of extinction in terms of frequency of CRs or amplitudes over $15 \mathrm{~d}$ of extinction training. However, there was no significant difference in percent or frequency of CRs between these animals and a control group with lobule HVI lesions. The control lesion animals did show significant extinction in terms of response amplitude, but the anterior lesion animals did not. In an earlier study, lesions of HVI, although retarding acquisition somewhat, had no effect on rate of extinction, which occurred over several days in both lesion and control animals (Weiss et al. 1991). However, in the K.S. Garcia et al. (1999) study, the CR amplitudes of the anterior-lesioned animals were extremely low, perhaps a basement effect, whereby the already lowamplitude responses cannot be reduced any further, and therefore, no extinction can be observed.

Medina et al. (2001) reported that picrotoxin infusion in the interpositus nucleus revealed short latency CRs during training, and also revealed the presence of such short latency CRs after 45 $\mathrm{d}$ of extinction training, when no CRs occurred in the absence of picrotoxin, suggesting that the memory is preserved to some degree in the interpositus nucleus. However, they did not give untrained animals $45 \mathrm{~d}$ of tone-alone exposures to control for nonassociative effects. This is critically important, as it has recently been shown that infusion of picrotoxin in the interpositus nucleus can result in the performance of short-latency $95 \mathrm{~dB}$ tone-evoked eyeblink responses in untrained animals (Poulos et al. 2003). It is also the case that if the memory is indeed preserved in the interpositus nucleus, then unit recordings there should reveal some trace of it, and they do not (Gould and Steinmetz 1996). But it is always possible that the residual memory trace following extinction is below threshold for increased probability of action potentials.

We used the Purkinje cell-deficient (pcd) mice to explore the essential role of the cerebellar cortex in acquisition and extinction of the conditioned eyeblink responses. In this mutant, cerebellar development proceeds normally until about 2 wk after birth, at which time all Purkinje neurons in the cerebellar cortex die. Hence, the cerebellar cortex becomes completely nonfunctional. These animals show a slower rate of acquisition and reach a lower asymptotic of CR performance, but do show very sub- 
stantial and highly significant learning of the eyeblink CR (Chen et al. 1996). However, if the interpositus nucleus is lesioned in these mutants prior to training, they are completely unable to learn the eyeblink $\mathrm{CR}$, arguing that the learning occurs in the interpositus nucleus (Chen et al. 1999). These results seem to contradict other cerebellar cortical studies (i.e., Perret and Mauk 1995). Such conflicting results are more likely due to a variability in the lesions. Complete removal of the cortex is extremely difficult, and such large lesions likely result in damage to the deep nuclei.

Using a different methodological approach, these studies of the pcd mouse argue strongly that the cerebellar cortex is not essential for acquisition of the eyeblink CR, although it is clearly necessary for normal learning. Importantly, after learning the eyeblink CR, pcd mice show normal, rapid extinction of the CR, arguing that the cortex is not essential for extinction either. However, this does not rule out the possibility suggested by Gould and Steinmetz (1996) that a memory trace remains in the cerebellar cortex after extinction of the CR. The critical test would be to retrain the pcd animals after extinction. If they showed no savings in reacquisition over initial acquisition, it would support their view.

\section{Context, the Hippocampus, and Extinction}

Although the hippocampus does not appear to play a critical role in standard delay eyeblink conditioning, it does play a key role in trace conditioning, where a period of no stimulation intervenes between CS offset and US onset. Specifically, hippocampal lesions made prior to training essentially prevent subsequent learning (anterograde amnesia) (Solomon et al. 1986; Moyer Jr. et al. 1990). If the lesions are made immediately after training, trace, but not delay CRs are abolished. However, if the lesions are made a month after training, the trace CR is not impaired at all (timelimited retrograde amnesia; Kim et al. 1995). These are, of course, the hallmarks of medial temporal lobe-hippocampal lesion impairment of declarative memories in humans (Squire 1987). One possible explanation of the key role of the hippocampus in trace conditioning concerns context. Perhaps the hippocampus somehow codes the context in order to bridge the gap between CS and US.

Penick and Solomon (1991) showed that the hippocampus appears to code context in eyeblink conditioning. After partial training, animals were given continued training in the same or different context. Context shift impaired CR performance in normal rabbits, but did not impair performance at all in hippocampal-lesioned animals. In fear conditioning, hippocampal lesions prevent learned fear to context but not to tone cue (Kim and Fanselow 1992).

Several studies indicate that CS alone extinction is markedly impaired by lesions of the hippocampus, regardless of whether CRs were established with delay or trace-conditioning procedures. Schmaltz and Theios (1972) demonstrated that bilateral hippocampal lesions made prior to delay conditioning were associated with a higher level of CR expression through much of extinction training than cortical-lesioned control animals. More recently, Akase et al. (1989) trained eyeblink conditioning using the standard delay procedure in hippocampectomized rabbits. In well-trained animals, there was essentially no extinction in a subsequent $\mathrm{CS}$ alone training session.

Even more dramatic, Moyer Jr. et al. (1990) showed that hippocampal-lesioned rabbits given short interval (300 msec) trace conditioning learned normally, but showed no evidence of extinction over three sessions, in contrast to sham and neocortical control lesions, which showed normal extinction.

There is growing evidence that contextual cues other than the CS can exert control of the CR in extinction. Frohardt et al. (2000) have demonstrated in Pavlovian fear conditioning that following extinction, presentation of the US alone reinstates the CR to the CS. However, if the postextinction presentation of the US occurs in a different context, reinstatement of the CR does not occur. Along similar lines, if the context in which CR acquisition occurs is followed by extinction in a second context, return to the original context will renew the expression of the CR to the once extinguished tone. Interestingly, lesions of the hippocampus specifically disrupt CR reinstatement, while resulting in no discernable effects on CR renewal.

There is recent evidence that prolonged exposure to the training context can result in extinction-like reductions of conditioned eyeblink responses (E.J. Kehoe, pers. comm.). In these studies, rabbits were trained to both tone and light CSs and then exposed solely to the training context for $6 \mathrm{~d}$. The following day, animals were presented with either CS alone and showed virtually no CRs over the course of $4 \mathrm{~d}$. Subsequent CS-US reacquisition yielded CRs at a rate similar to tone alone extinction controls. Such results demonstrating that context exposure produces reductions in previously learned behaviors have been previously reported in cued avoidance and lick-suppression tasks (Gabriel 1970; Marlin 1981). However, to date, experiments examining hippocampal involvement in this context-dependent phenomenon have yet to be carried out.

\section{The NMDA Receptor}

The NMDA receptor, a widely distributed site of glutamate binding commonly investigated in the hippocampus, has been more recently implicated in extinction of conditioned eyeblink responses. Scavio et al. (1992) reported that posttraining intravenous injections of amphetamine, chlorpromazine, and scopolamine, which retarded CR acquisition, had no effect on extinction, whereas the NMDA receptor antagonist ketamine accelerated acquisition and decreased the rate of extinction. Kehoe et al. (1996) further elaborated the involvement of NMDA receptors by demonstrating that pretraining injections of MK801 completely prevent eyeblink extinction (but, see Takatsuki et al. 2001). Rabbits were administered MK-801 or saline prior to 6 d of extinction, during which MK-801-treated animals expressed virtually no CRs. However, when MK-801 administration was suspended, CRs reappeared immediately and showed no evidence of the previous extinction treatment. In contrast, Thompson and Disterhoft (1997) showed that injections of high doses of MK-801 or another NMDA receptor antagonist phencyclidine failed to effect the expression of trace or delay CRs, yet completely prevented extinction.

These studies suggest NMDA receptors play some role in extinction of conditioned eyeblink responses. There is an abundance of literature indicating that NMDA receptors are involved in the acquisition and retention of a number of learning tasks, including eyeblink conditioning. Chen and Steinmetz (2000) showed that cerebellar infusions of NMDA receptor antagonist AP5 into the interpositus nucleus severely attenuate the acquisition of conditioned eyeblink responses. As for eyeblink extinction, relevant substances have only been administered systemically, so it is not possible to localize their effects on brain structures.

\section{Conclusion}

The collective behavioral evidence presented here strongly suggests that extinction of classically conditioned discrete motor responses involves the learning of a new inhibitory association while maintaining the original excitatory association. Further, the results from neuronal studies demonstrate that the brain sub- 
strates for extinction, to some extent, differ from those of acquisition.

Both the cerebellar cortex and the interpositus nucleus have been implicated in preserving the memory of the eyeblink CR following extinction training, but the jury is still out. In terms of putative mechanisms, cerebellar cortical LTD and LTP at parallelfiber Purkinje neuron dendrites are certainly candidates (Ito 1984), particularly as LTD is postsynaptic and LTP is presynaptic at these synapses. Linden and associates have identified a number of possible sites of synaptic and nonsynaptic plasticity in cerebellar cortex and nuclei that could subserve acquisition (and its maintenance in extinction), on the basis of studies of cerebellar tissue culture and slice (Hansel et al. 2001). The dramatic demonstration by Kleim et al. (2002) of a selective increase in excitatory synapses in the interpositus nucleus following eyeblink conditioning raises the possibility that some degree of preservation of this increase could serve to maintain the memory in extinction. It will be critically important to determine this. However, the possibility that the hippocampus may play a key role in extinction of the conditioned eyeblink response must also be explored further.

\section{ACKNOWLEDGMENTS}

This research was supported by National Science Foundation Grant IBN-9215069.

\section{REFERENCES}

Akase, E., Alkon, D.L., and Disterhoft, J.F. 1989. Hippocampal lesions impair memory of short-delay conditioned eye blink in rabbits. Behav. Neurosci. 103: 935-943.

Albus, J.S. 1971. A theory of cerebellar function. Math. Biosci. 10: 25-61.

Bailey, D.J., Kim, J.J., Sun, W., Thompson, R.F., and Helmstetter, F.J. 1999. Acquisition of fear conditioning in rats requires the synthesis of mRNA in the amygdala. Behav. Neurosci. 113: 276-282.

Barnet, R.C. and Miller, R.R. 1996. Second-order excitation mediated by a backward conditioned inhibitor. J. Exp. Psychol. Anim. Behav. Process 22: 279-296.

Bouton, M.E. 1984. Differential control by context in the inflation and reinstatement paradigms. J. Exper. Psychol.: Animal Behav. Proc. 10: $56-74$.

1993. Context, time, and memory retrieval in the interference paradigms of Pavlovian learning. Psychol. Bull. 114: 80-99.

. 2002. Context, ambiguity, and unlearning: Sources of relapse after behavioral extinction. Biol. Psych. 52: 976-986.

Bouton, M.E. and Swartzentruber, D. 1991. Sources of relapse after extinction in Pavlovian and intrumental learning. Clin. Psychol. Rev. 11: $123-140$.

Brodal, P. and Brodal, A. 1981. The olivocerebellar projection in the monkey. Experimental studies with the method of retrograde tracing of horseradish peroxidase. J. Comp. Neurol. 201: 375-393.

Brooks, D.C. 2000. Recent and remote extinction cues reduce spontaneous recovery. Q. J. Exp. Psychol. B 53: 25-58.

Brooks, D.C. and Bowker, J.L. 2001. Further evidence that conditioned inhibition is not the mechanism of an extinction cue's effect: A reinforced cue prevents spontaneous recovery. Anim. Learn. Behav. 29: $381-388$.

Brooks, D.C, Palmatier, M.I., Garcia, E.O, and Johnson, J.L. 1999. An extinction cue reduces spontaneous recovery of a conditioned taste aversion. Anim. Learn. Behav. 27: 77-88.

Cain, C.K., Blouin, A.M., and Barad, M. 2002. L-type voltage-gated calcium channels are required for extinction, but not for acquisition or expression, of conditional fear in mice. J. Neurosci. 22: 9113-9121.

Chen, G. and Steinmetz, J.E. 2000. Intra-cerebellar infusion of NMDA receptor antagonist AP5 disrupts classical eyeblink conditioning in rabbits. Brain Res. 887: 144-156.

Chen, L., Bao, S., Lockard, J.M., Kim, J.K., and Thompson, R.F. 1996. Impaired classical eyeblink conditioning in cerebellar-lesioned and Purkinje cell degeneration (pcd) mutant mice. J. Neurosci. 16: 2829-2838.

Chen, L., Bao, S., and Thompson, R.F. 1999. Bilateral lesions of the interpositus nucleus completely prevent eyeblink conditioning in Purkinje cell-degeneration mutant mice. Behav. Neurosci. 113: 204-210.

Christian, K.M. and Thompson, R.F. 2003. Neural substrates of eyeblink conditioning: Acquisition and retention. Learn. Mem. 10: 427-455. Clark, R.E., Zhang, A.A., and Lavond, D.G. 1992. Reversible lesions of the cerebellar interpositus nucleus during acquisition and retention of a classically conditioned behavior. Behav. Neurosci. 106: $879-888$.

Delamater, A.R. 1996. Effects of several extinction treatments upon the integrity of Pavlovian stimulus-outcome associations. Anim. Learn. Behav. 24: $437-449$.

Eccles, J.C. 1977. An instruction-selection theory of learning in the cerebellar cortex. Brain Res. 127: 327-352.

Falls, W.A. 1998. Extinction: A review of theory and evidence suggesting that memories are not erased with non-reinforcement. In Learning and behavior therapy (ed. W. O'Donohue), pp. 205-229. Allyn and Bacon, Boston, MA.

Falls, W.A., Miserendino, M.J., and Davis, M. 1992. Extinction of fear-potentiated startle: Blockade by infusion of an NMDA antagonist into the amygdala. J. Neurosci. 12: 854-863.

Frohardt, R.J., Guarraci, F.A., and Bouton, M.E. 2000. The effects of neurotoxic hippocampal lesions on two effects of context after fear extinction. Behav. Neurosci. 114: 227-240.

Gabriel, M. 1970. Intersession exposure of rabbits to conditioning apparatus, avoidance extinction, and intertrial behavior. J. Comp. Physiol. Psychol. 72: 244-249.

Garcia, K.S., Steele, P.M., and Mauk, M.D. 1999. Cerebellar cortex lesions prevent acquisition of conditioned eyelid responses. $J$. Neurosci. 19: 10940-10947.

Garcia, R., Vouimba, R.M., Baudry, M., and Thompson, R.F. 1999. The amygdala modulates prefrontal cortex activity relative to conditioned fear. Nature 402: 294-296.

Gewirtz, J.C., Falls, W.A., and Davis, M. 1997. Normal conditioned inhibition and extinction of freezing and fear-potentiated startle following electrolytic lesions of medical prefrontal cortex in rats. Behav. Neurosci. 111: 712-726.

Gould, T.J. and Steinmetz, J.E. 1996. Changes in rabbit cerebellar cortical and interpositus nucleus activity during acquisition, extinction and backward classical eyelid conditioning. Neurobiol. Learn. Mem. 65: 17-34.

Hansel, C., Linden, D.J., and D'Angelo, E. 2001. Beyond parallel fiber LTD: The diversity of synaptic and nonsynaptic plasticity in the cerebellum. Nat. Neurosci. 4: 467-475.

Hardiman, M.J., Glickstein, M., and Yeo, C.H. 1988. Kainic acid lesions of the cerebellar cortex abolish the classically conditioned nictitating membrane response of the rabbit. Abstr. Soc. Neurosci. 14: 784 .

Hardiman, M.J., Ramnani, N., and Yeo, C.H. 1996. Reversible inactivations of the cerebellum with muscimol prevent the acquisition and extinction of conditioned nictitating membrane responses in the rabbit. Exp. Brain Res. 110: 235-247.

Herry, C. and Garcia, R. 2002. Prefrontal cortex long-term potentiation, but not long-term depression, is associated with the maintenance of extinction of learned fear in mice. J. Neurosci. 22: 577-583.

Hesslow, G. and Ivarsson, M. 1996. Inhibition of the inferior olive during conditioned responses in the decerebrate ferret. Exp. Brain Res. 110: $36-46$.

Holland, P.C. and Rescorla, R.A. 1975. Second-order conditioning with food unconditioned stimulus. J. Comp. Physiol. Psychol. 88: 459-467.

Ito, M. 1982. Experimental verification of Marr-Albus' plasticity assumption for the cerebellum. Acta. Biol. 33: 189-199. . 1984. The modifiable neuronal network of the cerebellum. J. Physiol. 34: 781-792.

Kamin, L.J. 1969. Predictability, surprise, attention, and conditioning. In Punishment and aversive behavior (eds. B.A. Campbell and R.M. Church), pp. 276-296. Appleton-Century-Crofts, New York.

Kehoe, E.J., Morrow, L.D., and Holt, P.E. 1984. General transfer across sensory modalities survives reductions in the original conditioned reflex in the rabbit. Anim. Learn. Behav. 12: 129-136.

Kehoe, E.J., Macrae, M., and Hutchinson, C.L. 1996. Mk-801 protects conditioned responses from extinction in the rabbit nictitating membrane preparation. Psychobiology 24: 127-135.

Kim, J.J. and Fanselow, M.S. 1992. Modality-specific retrograde amnesia of fear. Science 256: 675-677.

Kim, J.J., Clark, R.E., and Thompson, R.F. 1995. Hippocampectomy impairs the memory of recently, but not remotely, acquired trace eyeblink conditioned responses. Behav. Neurosci. 109: 195-203.

Kim, J.J., Krupa, D.J., and Thompson, R.F. 1998. Inhibitory cerebello-olivary projections and blocking effect in classical conditioning. Science 279: 570-573.

Kleim, J.A., Freeman, J.H., Bruneau, R., Nolan, B.C., Cooper, N.R., Zook, A., and Walters, D. 2002. Proc. Natl. Acad. Sci. 99: 13228-13231.

\section{Learning \& Memory}


Krupa, D.J. and Thompson, R.F. 1997. Reversible inactivation of the cerebellar interpositus nucleus completely prevents acquisition of the classically conditioned eye-blink response. Learn. Mem. 3: $545-556$. . 2003. Inhibiting the expression of a classically conditioned behavior prevents its extinction. J. Neurosci. 23: 10577-10584.

Krupa, D.J., Thompson, J.K., and Thompson, R.F. 1993. Localization of a memory trace in the mammalian brain. Science 260: 989-991.

Krupa, D.J., Weng, J., and Thompson, R.F. 1996. Inactivation of brainstem motor nuclei blocks expression but not acquisition of the rabbit's classically conditioned eyeblink response. Behav. Neurosci. 110: $219-227$.

Lattal, K.M. and Abel, T. 2001. Different requirements for protein synthesis in acquisition and extinction of spatial preferences and context-evoked fear. J. Neurosci. 21: 5773-5780.

Lavond, D.G., Steinmetz, J.E., Yokaitis, M.H., and Thompson, R.F. 1987. Reacquisition of classical conditioning after removal of cerebellar cortex. Exp. Brain Res. 67: 569-593.

Lee, H. and Kim, J.J. 1998. Amygdalar NMDA receptors are critical for new fear learning in previously fear-conditioned rats. J. Neurosci. 18: $8444-8454$.

Logan, C. 1991. Cerebellar cortical involvement in excitatory and inhibitory classical conditioning. Stanford University, Palo Alto, CA.

Macrae, M. and Kehoe, E.J. 1999. Savings after extinction in conditioning of the rabbit's nictitating membrane response. Psychobiology 27: 85-94.

Marlin, N.A. 1981. Within-compound associations between the context and the conditioned stimulus. Learn. Motiv. 13: 526-531.

Mauk, M.D., Steinmetz, J.E., and Thompson, R.F. 1986. Classical conditioning using stimulation of the inferior olive as the unconditioned stimulus. Proc. Natl. Acad. Sci. 83: 5349-5353.

McCormick, D.A. and Thompson, R.F. 1984. Neuronal responses of the rabbit cerebellum during acquisition and performance of a classically conditioned nictitating membrane-eyelid response. J. Neurosci. 4: $2811-2822$.

McCormick, D.A., Steinmetz, J.E., and Thompson, R.F. 1985. Lesions of the inferior olivary complex cause extinction of the classically conditioned eyeblink response. Brain Res. 359: 120-130.

Medina, J.F., Garcia, K.S., and Mauk, M.D. 2001. A mechanism for savings in the cerebellum. J. Neurosci. 21: 4081-4089.

Medina, J.F., Nores, W.L., and Mauk, M.D. 2002. Inhibition of climbing fibres is a signal for the extinction of conditioned eyelid responses. Nature 416: 330-333.

Milad, M.R. and Quirk, G.J. 2002. Neurons in medial prefrontal cortex signal memory for fear extinction. Nature 420: 70-74.

Mintz, M., Lavond, D.G., Zhang, A.A., Yun, Y., and Thompson, R.F. 1994. Unilateral inferior olive NMDA lesion leads to unilateral deficit in acquisition and retention of eyelid classical conditioning. Behav. Neural. Biol. 61: 218-224.

Montarolo, P.G., Palestini, M., and Strata, P. 1982. The inhibitory effect of the olivocerebellar input on the cerebellar Purkinje cells in the rat. J. Physyol. 332: 187-202.

Morgan, M.A., Romanski, L.M., and LeDoux, J.E. 1993. Extinction of emotional learning: Contribution of medial prefrontal cortex. Neurosci. Lett. 163: 109-113.

Moyer Jr., J.R., Deyo, R.A., and Disterhoft, J.F. 1990. Hippocampectomy disrupts trace eye-blink conditioning in rabbits. Behav. Neurosci. 104: $243-252$.

Myers, K.M. and Davis, M. 2002. Behavioral and neural analysis of extinction. Neuron 36: 567-584.

Napier, R.M., Macrae, M., and Kehoe, E.J. 1992. Rapid reaquisition in conditioning of the rabbit's nictitating membrane response. J. Exper. Psych.: Anim. Behav. Processes 18: 182-192.

Nelson, B.J., Adams, J.C., Barmack, N.H., and Mugnaini, E. 1989. Comparative study of glutamate decarboxylase immunoreactive boutons in the mammalian inferior olive. J. Comp. Neurol. 286: $514-539$.

Nordholm, A.F., Thompson, J.K., Dersarkissian, C., and Thompson, R.F. 1993. Lidocaine infusion in a critical region of cerebellum completely prevents learning of the conditioned eyeblink response. Behav. Neurosci. 107: 882-886.

Nores, W.L., Medina, J.F., Steele, P.M., and Mauk, M.D. 2000. Relative contributions of cerebellar cortex and cerebellar nucleus to eyelid conditioning. In Eyeblink classical conditioning: Animal model (eds. D.S. Woodruff-Pak and J.E. Steinmetz), Kluwer Academic Publishers, Boston, MA.

Pavlov, I.P. 1927. Conditioned Reflexes. Oxford University Press, London.

Penick, S. and Solomon, P.R. 1991. Hippocampus, context, and conditioning. Behav. Neurosci. 105: 611-617.

Perrett, S.P. and Mauk, M.D. 1995. Extinction of conditioned eyelid responses requires the anterior lobe of cerebellar cortex. J. Neurosci. 15: 2074-2080.
Poulos, A.M., Nobuta, H., and Thompson, R.F. 2003. Effects of intracerebellar infusion of picrotoxin on sensory stimulation. Abstr. Soc. Neurosci. 29: 87.19.

Quirk, G.J., Russo, G.K., Barron, J.L., and Lebron, K. 2000. The role of ventromedial prefrontal cortex in the recovery of extinguished fear. I. Neurosci. 20: 6225-6231.

Ramnani, N. and Yeo, C.H. 1996. Reversible inactivations of the cerebellum prevent the extinction of conditioned nictitating membrane responses in rabbits. J. Physiol. 495: 159-168.

Rescorla, R.A. 1995. Full preservation of a response-outcome association through training with a second outcome. Quar. J. Exper. Psychol. Comp. and Physiol. Psychol. 48B: 252-261.

. 1997. Response-inhibition in extinction. Quar. J. Exper. Psychol. 50: $238-252$.

Rescorla, R.A. and Heth, C.D. 1975. Reinstatement of fear to an extinguished conditioned stimulus. J. Exper. Psych.: Anim. Behav. Processes 1: 88-96.

Rescorla, R.A. and Skucy, J. 1969. Effect of response-independent reinforcers during extinction. J. Comp. and Physiolog. Psychol. 67: 381-389.

Rescorla, R.A. and Wagner, A.R. 1972. A theory of Pavlovian conditioning: Variations in the effectiveness of reinforcement and nonreinforcement. In Classical conditioning II: Current theory and research (eds. A.H. Black and W.F. Prokasy), pp. 64-99. Appleton-Century-Crofts, New York.

Robleto, K. and Thompson, R.F. 2003. Effects of muscimol infusions on the extinction of the classically conditioned nictitating membrane response in the rabbit. 2003 Abstract Viewer/Itinerary Planner. Program No. 87.6. Society for Neuroscience. Online. Washington, DC.

Santini, E., Muller, R.U., and Quirk, G.J. 2001. Consolidation of extinction learning involves transfer from NMDA-independent to NMDA-dependent memory. J. Neurosci. 21: 9009-9017.

Savio, T. and Tempia, F. 1985. On the Purkinje cell activity increase induced by suppression of inferior olive activity. Exp. Brain Res. 57: 456-463.

Scavio, M.J. and Thompson, R.F. 1979. Extinction and reacquisition performance alternations of the conditioned nictitating membrane response. Bull. Psych. Soc. 13: 57-60.

Scavio, M.J., Clift, P.S., and Wills, J.C. 1992. Posttraining effects of amphetamine, chlorpromazine, ketamine, and scopolamine on the acquisition and extinction of the rabbit's conditioned nictitating membrane response. Behav. Neurosci. 106: 900-908.

Schmaltz, L.W. and Theios, J. 1972. Acquisition and extinction of a classically conditioned response in hippocampectomized rabbits (Oryctolagus cuniculus). J. Comp. Physiol. Psychol. 79: 328-333.

Schreurs, B.G. 1993. Long-term and extinction of the classically conditioned rabbit nictitating membrane response. Learn. Motiv. 24: 293-302.

1998. Long-term memory and extinction of rabbit nictitating membrane trace conditioning. Learn. Motiv. 29: 68-82.

Sears, L.L. and Steinmetz, J.E. 1991. Dorsal accessory inferior olive activity diminishes during acquisition of the rabbit classically conditioned eyelid response. Brain Res. 545: 114-122.

Smith, M. and Gormezano, I. 1965. Effects of alternating classical conditioning and extinction sessions on the conditioned nictitating membrane response of the rabbit. Psychon. Sci. 3: $91-92$.

Solomon, P.R., Vander Schaaf, E.R., Thompson, R.F., and Weisz, D.J. 1986. Hippocampus and trace conditioning of the rabbit's classically conditioned nictitating membrane response. Behav. Neurosci. 100: $729-744$.

Squire, L.R. 1987. Memory and brain. Oxford University Press, New York. Steinmetz, J.E. 2000. Brain substrates of classical eyeblink conditioning: A highly localized but also distributed system. Behav. Brain Res. 110: $13-24$.

Steinmetz, J.E., Lavond, D.G., and Thompson, R.F. 1989. Classical conditioning in rabbits using pontine nucleus stimulation as a conditioned stimulus and inferior olive stimulation as an unconditioned stimulus. Synapse 3: 225-233.

Tait, R.W. and Saladin, M.E. 1986. Concurrent development of excitatory and inhibitory associations during backward conditioning. Anim. Learn. Behav. 14: 133-137.

Takatsuki, K., Kawahara, S., Takehara, K., Kishimoto, Y., and Kirino, Y. 2001. Effects of the noncompetitive NMDA receptor antagonist MK-801 on classical eyeblink conditioning in mice. Neuropharmacology 41: 618-628.

Thompson, R.F. 1989. Role of the inferior olive in classical conditioning. Exp. Brain Res. 17: 347-362.

Thompson, R.F. and Krupa, D.J. 1994. Organization of memory traces in the mammalian brain. Annu. Rev. Neurosci. 17: 519-549. 
Thompson, L.T. and Disterhoft, J.F. 1997. N-methyl-D-aspartate receptors in associative eyeblink conditioning: Both MK-801 and phencyclidine produce task- and dose-dependent impairments. $J$. Pharmacol. Exp. Ther. 281: 928-940.

Thompson, R.F., Bao, S., Chen, L., Cipriano, B.D., Grethe, J.S., Kim, J.J., Thompson, J.K., Tracy, J.A., Weninger, M.S., and Krupa, D.J. 1997. Associative learning. Int. Rev. Neurobiol. 41: 151-189.

Thompson, R.F., Thompson, J.K., Kim, J.J., Krupa, D.J., and Shinkman, P.G. 1998. The nature of reinforcement in cerebellar learning. Neurobiol. Learn. Mem. 70: 150-176.

Voneida, T.J., Christie, D., Bogdanski, R., and Chopko, B. 1990. Changes in instrumentally and classically conditioned limb-flexion responses following inferior olivary lesions and olivocerebellar tractotomy in the cat. J. Neurosci. 10: 3583-3593.

Wagner, A.R. 1971. Elementary associations. In Essays in neobehaviourism: A memorial volume to Kenneth W. Spence. (eds. H.H. Kendler and J.T. Spence). Appleton-Century-Crofts, New York.

Weiss, C., Logan C.G., and Thompson, R.F. 1991. Effects of cerebellar cortical lesions on Extinction and reacquisition of NM conditioning in rabbits. Abstr. Soc. Neurosci. 17: 869.

Welsch, J.P. and Harvey, J.A. 1998. Acute inactivation of the inferior olive blocks associative learning. Eur. J. Neurosci. 10: 3321-3332.

Woodruff-Pak, D.S. and Steinmetz, J.E. 2000. Eyeblink classical conditioning: Animal models. Kluwer Academic Publishers, Boston, MA.

Woodruff-Pak, D.S, Lavond, D.G., and Thompson, R.F. 1985. Trace conditioning: Abolished by cerebellar nuclear lesions but not lateral cerebellar cortex aspirations. Brain Res. 348: 249-260.

Yeo, C.H. 2004. Memory and the cerebellum. Curr. Neurol. Neurosci. Rep. 4: $87-89$.

Yeo, C.H. and Hesslow, G. 1998. Cerebellum and conditioned reflexes. Trends Cogn. Sci. 2: 322-330.

Yeo, C.H., Hardiman, M.J., and Glickstein, M. 1984. Discrete lesions of the cerebellar cortex abolish the classically conditioned nictitating membrane response of the rabbit. Behav. Brain Res. 13: 261-266.

- 1986. Classical conditioning of the nictitating membrane response of the rabbit. IV. Lesions of the inferior olive. Exp. Brain Res. 63: 81-92. 


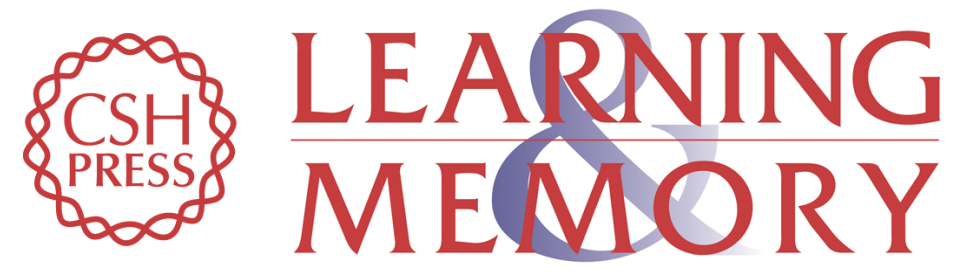

\section{Brain Mechanisms of Extinction of the Classically Conditioned Eyeblink Response}

Karla Robleto, Andrew M. Poulos and Richard F. Thompson

Learn. Mem. 2004, 11:

Access the most recent version at doi:10.1101//m.80004

References This article cites 93 articles, 22 of which can be accessed free at: http://learnmem.cshlp.org/content/11/5/517.full.html\#ref-list-1

License

Email Alerting

Receive free email alerts when new articles cite this article - sign up in the box at the Service top right corner of the article or click here. 